Meta

Journal des traducteurs

Translators' Journal

\title{
Descriptive Terminology: Some Theoretical Implications
}

\section{Wayne D. Cole}

Volume 36, numéro 1, mars 1991

La terminologie dans le monde : orientations et recherches

URI : https://id.erudit.org/iderudit/002347ar

DOI : https://doi.org/10.7202/002347ar

Aller au sommaire du numéro

Éditeur(s)

Les Presses de l'Université de Montréal

ISSN

0026-0452 (imprimé)

Découvrir la revue

Citer cet article

Cole, W. D. (1991). Descriptive Terminology: Some Theoretical Implications. Meta, 36(1), 16-22. https://doi.org/10.7202/002347ar

\section{Résumé de l'article}

En terminologie, la théorie est basée sur les recherches menées dans les domaines scientifique et technique (ST). Or, les principes qui y régissent le travail terminologique ne sont pas nécessairement universellement applicables. En réalité, les théories s'appuyant sur des recherches effectuées en domaines ST sont trop strictes et souvent inapplicables pour le travail terminologique dans d'autres secteurs, spécialement dans le domaine des sciences humaines. Cela n'empêche pas les terminologues de ces domaines de poursuivre leurs recherches et de produire des lexiques de qualité. Néanmoins, il convient de réévaluer les principes sur lesquels repose la théorie de la terminologie. 


\title{
DESCRIPTIVE TERMINOLOGY: SOME THEORETICAL IMPLICATIONS
}

\author{
WAYNe D. COLE \\ Department of the Secretary of State of Canada, Hull. Canada
}

RÉSUMÉ

En terminologie, la théorie est basée sur les recherches menées dans les domaines scientifique et technique (ST). Or, les principes qui y régissent le travail terminologique ne sont pas nécessairement universellement applicables. En réalité, les théories s'appuyant sur des recherches effectuées en domaines ST sont trop strictes et souvent inapplicables pour le travail terminologique dans d'autres secteurs, spécialement dans le domaine des sciences humaines. Cela n'empêche pas les terminologues de ces domaines de poursuivre leurs recherches et de produire des lexiques de qualité. Néanmoins, il convient de réévaluer les principes sur lesquels repose la théorie de la terminologie.

Much of the current theory of terminology is based on the examination of terminological research results in scientific and technical fields. In light of research carried out in other subject areas, consideration of some of the widely accepted tenets of this theory indicates that these tenets are less universally applicable than is usually asserted. By presenting examples from such other areas it is hoped that an accurate assessment of the limitations of current theory can be provided. As well, an orientation for theoretical studies will be indicated which may permit the development of structures having a wider application.

In the normal course of its development, a discipline begins with poorly defined data and with an imprecise, rudimentary theoretical framework. As work progresses, the data become better defined and more reliable, aided by theoretical refinements; the theory becomes more precise and more comprehensive, aided by the improved data on which it can base itself.

An interesting feature of this development is that, ordinarily, it is not uniform. More reliable data will be found in one area than in others, or some aspect of the theory will be perfected while no progress is made elsewhere. A temporary bias in the overall development of the discipline may result. The existence of some mature theoretical structures will make it easier to carry out work in the areas to which they apply; theorizing, in its turn, advances more rapidly concerning aspects of its subject matter for which reliable data exist.

Each of these situations, however, brings with it its own particular risk of error. Concentration on certain aspects of a theory to the exclusion of others may create an imbalance which actually hampers research in areas to which those aspects do not apply. Theorizing on the basis of data from a single subdivision of a discipline may lead to generalizations which prove, in the end, to apply not to the discipline as a whole, but only to that area from which the data first arose. These two errors are complementary, and once they have been committed, they tend to reinforce one another.

It is the contention of this paper that just such a situation exists at present in terminology. There is a tendency among theorists to extend principles derived from the examination of the terms used in one area to the whole of terminology. 
When discussing terms, or the subject fields in which they are used, most works on terminology make use of the expression scientific and technical to describe them. The word technical is often used either ambiguously or equivocally in such contexts. Although technical may be taken to mean any field of specialized activity, it is most often used of fields which might better be termed technological, that is, the fields of applied science. Even when it is used ostensibly in the broader sense, most of the literature ignores fields outside of the scientific and technological (ST) area. While it is by no means illegitimate to give careful examination to ST fields and the terminologies they use, it is, at the same time, an unwarranted assumption to think that what proves to be true of terms in ST fields will be true (or, as is also often assumed, either explicitly or implicitly, that it ought to be true) of terms in other fields.

At any rate, many of the central principles of theoretical terminology appear to be based exclusively upon an examination of ST fields. As will be shown below, their applicability to other fields (and, hence, their claim to generality) is, at the least, questionable.

Descriptive terminology is, for the most part, user driven. It is carried out in order to provide clients (in Canada, these are mainly either translators or others whose activities include translation) with a compilation of the terms used in some particular area of interest to them. The field in which work is to be done is thus stipulated by the end user rather than by the terminologist (although other factors may necessitate some negotiation concerning the scope of a given project). There exists a significant demand for the compilation of glossaries and vocabularies in fields which are not considered a part of ST terminology. As a rough measure of this demand, nearly one third of the terminology records (approximately 285,000) in TERMIUM, the Canadian government's termbank, are classed in non-ST fields. The demand for such terminology is, if anything, on the increase. All areas of human activity are tending toward a greater utilization of subjectspecific concepts, with an accompanying body of terms to designate them.

The ST fields share a number of features which are not typically found elsewhere, although one or several of them may also be found to characterize other fields. They rely on objective (or intersubjective) standards of observation and measurement, the goals of their activities are specific and the concepts and conceptual relations which they use are explicitly defined. These concepts and their relations are subject to public scrutiny and revision by the appropriate specialist community. It is the definiteness of their conceptual structures and the fact that they pursue single, precise objectives that are their important characteristics for terminology.

In non-ST areas, however, these characteristics are not present or may only be present to a certain degree. The field of staffing may serve as an example. In the first place, the objective of the staffing process - to procure the best possible candidate to fill a given position - does not conform to the theory which derives from the ST standard. "Best possible" lacks the definiteness that was noted as characteristic of the ST fields. Its being characterized, in part, by an element of value judgement results in individual interpretation playing an essential role, a fact which is in turn reflected in the procedures actually used in the field. Not only are different procedures used to fill positions at different levels or of different types within a single organization, but these procedures also differ from organization to organization. The procedures used for recruiting systems management and engineering staff differ markedly from those for recruiting personnel for fast-food restaurants.

There are two points of interest in the above example. First, it is clear that the objective which directs the activity of a subject field need not be definite; it can leave wide scope for interpretation depending on individual circumstances. It should be pointed 
out that the lack of definiteness here is intrinsic and not accidental. Further study will not lead to a more precise overall enunciation of the basic objective. This is true of all fields where elements of human judgement play an integral role in the attainment of objectives, such as administration, law and finance.

Secondly, as a consequence of the point made above, it is evident that such fields are not monolithic in the same way that ST fields are. For example, the concepts and procedures used by chemists are the same the world over, but the administration of a given organization may differ significantly from that of another housed in the same building. This is of particular importance for terminology. A glossary of staffing procedures in general would apply to no organization in particular. As such, it is unlikely that anyone would ever request the production of such a document. Requests for glossaries dealing with the administration of a specific organization are in far greater demand. Many such documents exist, but as they tend to be used exclusively in-house, their actual importance is often substantially undervalued.

While it is true that a subject field may be defined, in general, as an area of specific activity or study, it is evident that the degree to which it is specific can vary widely from one field to another. The actual limits of what can constitute a subject field are open to question. Even the divisions between ST fields are often regarded as arbitrary and as subject to change in the light of subsequent scientific discoveries and technological advances.

The proper delimitation of subject fields is a necessary part of terminology's onomasiological orientation. To the extent that this issue has received attention, the focus has been more on purely classificatory, rather than terminological, points. The link between subject fields and concepts is one which deserves more attention. The fact that a subject field may not make use of a single network of concepts (and may, in consequence, contain several, frequently divergent, terminologies) might seem to call into question its very right to be regarded as a subject field. Alternatively, it may be more fruitful to reexamine the question as a whole, taking into account for the purposes of that examination a wider range of (potential) subject fields than the ST region offers.

Another aspect of theory which should be reexamined is that of the role of the concept network in terminology. As words or expressions come to be deemed terms by virtue of their designating a specific concept, the correct delimitation of the concept itself is a necessary precondition for the identification of the corresponding term. Every subject field contains a number of concepts which are interrelated in a network; in order to properly delimit a given concept it is necessary to map out its place in that network.

Here, as well, the paradigmatic role of ST fields is evident. As pointed out above, ST fields tend to be very definite about their conceptual structure, and about the contents of the individual constituent concepts. Although difficulties may be encountered in completely identifying such networks, particularly in the pure sciences, ST fields in general lend themselves to this type of conceptual analysis. Fields in which an element of value judgement is an essential constituent may not permit similar analysis. In the first place, the general organizational principle of such non-ST fields (the objective of their distinctive activity) often lacks the sort of specificity found in ST fields. This feature alone may preclude a fully determinate conceptual structure.

Secondly, other elements that depend on value judgements are frequently encountered constituents of such fields. It is not the general principle alone but the subsidiary ones as well which depend upon the individual's capacity of judgement for their specific role in any given case. In such fields it is common for a certain amount of flexibility to exist. In staffing, for example, the role played by a selection interview may 
vary depending on the post to be staffed. Other elements of the selection process may be subordinated to it, superior to it, or it may itself be regarded as totally unnecessary.

It is true that technological processes can also be varied, that from one plant to another different equipment or processes may be employed. The end product of a technological process is, however, subject to exact specification. In order that the product meet the criteria imposed, the variations in production must also be subject to strict quantitative controls. In other non-ST fields the situation may be even more complex. For example, English (and Canadian) parliamentary law is based on four principles (Beauchesne 1989:3), which are not rigidly hierarchized. Guidance for the application of these principles, and for the resolution of conflicts between them, is drawn from four separate sources. In addition, difficulties may arise from attempts to subvert the stated objectives of the procedure used in Parliament to purely partisan or personal ends.

The possibility of determining an unambiguous conceptual network capable of commanding the assent of experts in such fields may be excluded out of hand. The absence of a discrete, definable concept network, as with the diffuse objectives of many non-ST subject fields which was noted above, is an intrinsic characteristic of such fields and does not represent a defect or a deficiency. It is incumbent upon the theory of terminology to recognize the actual natures of various fields and attempt to provide a coherent account of them, rather than suggesting that modifications be made to them in order that they may conform to an essentially extraneous standard. The purpose of theoretical terminology is to elicit those principles which lie concealed in the data produced by descriptive terminology; it is not part of its task to call for the restructuring of reality merely to accommodate its current methodological or philosophical presuppositions.

It should also be pointed out that, even where possible, the presentation of a complete concept network is rarely practicable and is largely forgone. No one has attempted to elaborate the concept network of chemistry, of organic chemistry or of the reaction mechanisms of halogenated, heterocyclic carbon compounds. The fact that so much reliable terminological research has been, and is being, carried out without these aids gives some indication of their real utility, or lack of it.

For descriptive terminology, the absence of a completely delineated concept network for a given field is not of particular importance. A complete analysis of this type, even where such is possible, is not necessary in order to identify individual concepts and the terms by which they are designated.

A requirement which must be met, however, is that any concept in a given field be clearly and unequivocally distinguished from those neighbouring concepts which might otherwise be confused with it. In some cases, then, it is necessary to make as explicit as possible the various relations which exist between relatively small clusters of concepts. Even this less stringent requirement may be difficult to meet in some non-ST fields. As indicated above, many relations between concepts are, at the general level, in a state of flux or indeterminacy. Specific circumstances may cause the relations to become fixed for a given case, but in other circumstances, different relational configurations may occur. All that descriptive terminology should do in such situations is to reflect the actual state of affairs, indicating the pertinent terminological consequences (the possibility of equivocation, of terms being used to designate more than one concept, etc.). Insofar as the terminological difficulties merely mirror the situation at the conceptual level, any resolution (if necessary) must be reached by subject-field experts, rather than by terminologists. These experts may, or may not, feel the need for the assistance of prescriptive terminology at some point, but the responsibility for the resolution of essentially conceptual matters lies with subject-field experts and not with terminologists. 
Concepts and concept networks must conform to the reality which they are intended to conceptualize. The requirement for an ST-type of orderliness and specificity (to the extent that it actually does exist) must not be imposed in areas of human activity which operate on different principles and strive to attain ends of a different type.

At the level of individual concepts, which make up an extremely diverse and often disparate collection, analysis is much more difficult. There exist numerous controversies concerning the nature of concepts, the relationship between concepts and their definitions, the adequacy of various types of definition and so on. These questions cannot be examined here, but it is possible to give at least some indication of the differences between ST concepts and those in other fields (without making any claim for the exhaustiveness of the characterizations).

Scientific concepts arise out of the conjunction of theory and observations, which are often precisely quantified and which are, at least in principle, duplicable. Technological concepts represent discrete, concrete physical entities and processes. In both cases, explicit enumeration and specificity of the characteristics serve to provide well-defined concepts, accepted by virtually the entire community of subject-field experts concerned. Even in cases where different hypotheses incorporate different concepts of the same entity or process, their common agreement concerning the existence of a phenomenon to be explained, and the deliberate prominence which they give to their disagreement, ordinarily obviate any terminological dispute. (The case of truly incommensurable theories is an exception to this, but the difficulties which arise when such theories confront one another are not primarily or essentially terminological although they are sometimes mistakenly believed to be so.)

Fields where individual interpretation is an essential element manifest this feature of their make-up in two ways at the level of individual concepts. The intention of a given concept - the actual contents of which it is made up-may contain characteristics which are open to interpretation. Subject-field experts in the humanities and social sciences frequently hold very different ideas concerning the concepts central to the irrespective studies. Anthropologists discuss the contents of the concept denoted by primitive (and whether it is a concept which properly has a place in anthropology); philosophers dispute with each other over the meaning of dialectic in the works of this or that thinker. To the extent that they base their decisions on their personal judgement of the worth of various elements (and not, say, on some measurement or even the consensus of their colleagues), there can be no ultimate settlement on a single concept. This is not merely the result of the existence of different schools of thought, but of the more fundamental feature of such concepts-that any analysis and understanding of them must be based, at least in part, on the individual's interpretation of some or all of their constituent characteristics.

This evaluative aspect is also reflected in determining the extension of a given concept. Granted a grasp of the characteristics of some concept, it still remains a matter of judgement whether such and such an object or event may be subsumed under it. For example, familiarity with a concept such as that designated by breach of privilege in the field of parliamentary law does not guarantee that there will be any agreement as to whether a particular act or statement may be properly described as constituting such a breach.

Neither of these two considerations causes, or, at least, need cause, any difficulty for terminology. In academic circles it is common for authors to stipulate the meaning of key concepts. Thus it is possible for subject field experts to disagree with one another (compare, for example, Nakos (1989a: 352) and Boulanger (1989: 360), on whether the concept designated by term includes syntagms) or even with themselves, at different 
times (compare Nakos 1989a: 352 and Nakos 1989b: 10 on the same point), without causing any confusion, either conceptual or terminological.

Questions concerning the actual extension of a concept of this type are not terminological in nature. They are matters to be settled by competent subject-field authorities.

As indicated above, it is unnecessary to have a completely determinate, exhaustive knowledge of a concept's contents in order to make the decision that it is designated by a given term. It is sufficient that whatever characterization one does possess be adequate to differentiate the concept from its neighbours. This may mean that what is an adequate characterization at one point, or for a specific purpose, may, at a later date or in another context, require further clarification or specification. What is essential is the validity of the designation - that a term does, in fact, designate a particular concept. It is not necessary to have, first, an absolutely encyclopedic definition of a concept before one can, with complete confidence, identify the term by which it is designated.

Three important conclusions can be drawn from the discussion presented here. The first is that the current theoretical emphasis on developing the principles of terminology in what is intended to be a scientific manner, has led to a standard which is too rigid and which, in non-ST fields, is often simply inappropriate. Fields need not consist of a single, universally accepted body of concepts; concept networks do not need to be unequivocally determined or even exist in a stable, static form; an understanding of individual concepts may involve an interpretive component and does not, for terminological purposes, necessarily require a complete enumeration of the concept's constituent characteristics.

The second conclusion is that, although principles derived from an examination of ST-fields are, in many areas, unsuitable as a guide for descriptive terminology, it is nonetheless possible for terminologists to conduct thorough, reliable research in those areas and to produce glossaries, etc., in which there is neither conceptual confusion nor incorrect attribution of terms. The ground of this possibility is found in the fact that subject-field experts do distinguish among the concepts they use, to the extent required by the study they are engaged in or the activity they pursue, and that they are, to an equal extent at least, fastidious with the terms they use to designate those concepts.

A corollary of this conclusion is that the principles scrutinized here, although they have arisen from an examination of ST fields and the terms employed therein, probably impose requirements that are unnecessarily stringent even in those fields themselves. That is, for example, that while ST fields may possess completely statable, unequivocal concept networks, comprised of very precisely and highly defined concepts, it does not follow that these networks need be fully stated or these concepts completely defined in order for the terminologist to adequately carry out research.

The third, and most important, conclusion concerns the necessity of reappraising the theory on which terminology bases itself. Such a reappraisal must take advantage of the enormous amount of descriptive work, especially that of the last ten years, which has been carried out in fields other than the scientific and technological. ST fields are and will remain important, and the need for clear, reliable communication within them will continue to grow. At the same time, the increasingly specialized nature of many other fields, in which equally legitimate communication needs to exist, makes their requirement for reliable terminological support no less pressing. Other problems, which have so far been confronted but not resolved - the existence, within a single field, of distinct types of specialized texts, with differing terminological requirements; the increasing penetration into general language of terms and concepts from specialized subject fields - can only be fully addressed by terminologists if they possess a theoretical 
framework having the broadest possible base. Only in this way will terminology be able to assume its proper role in helping to meet current and future communication needs.

\section{BIBLIOGRAPHY}

BEAUCHESNE, Arthur (1989): Beauchesne's Rules and Forms of the House of Commons of Canada: With Annotations, Comments and Precedents, 6th ed. by Alistair Fraser, W.F. Dawson and John A. Holby, Toronto, Carswell.

BOULANGER, Jean-Claude (1989): «Le statut du syntagme dans les dictionnaires généraux monolingues», Meta, 34-3, pp. 360-369.

DAHLBERG, I. (1985): "Begriffsbeziehungen und Definitionstheorie", Terminologie und benachbarte Gebiete: 1965-1985, Infoterm, Vienna, Bohlan.

DROZD, L. (1981a): "Some Remarks on a Linguistic Theory of Terminology", Infoterm Series 6, Theoretical and Methodological Problems of Terminology, München, K.G.Saur.

DROZD, L. (1981b): "Science terminologique: Objet et méthode", Fondements théoriques de la terminologie, Québec, GIRSTERM, Université Laval.

FELBER, H. (1981): "The Vienna School of Terminology", Infoterm Series 6: Theoretical and Methodological Problems of Terminology, München, K.G. Saur.

NAKOS, Dorothy (1989a): "Étude comparée des modes de formation des lexies complexes dans deux domaines différents", Meta, 34-3, pp. 352-359.

NAKOS, Dorothy (1989b): "Quelques difficultés de la traduction scientifique et technique", Terminology Update, 22-5, pp. 9-11.

RONDEAU, Guy (1984): Introduction à la terminologie, Chicoutimi, Québec, G. Morin.

SAGER, Juan C.., David DUNGWORTH and Peter F. McDONALD (1980): English Special Languages: Principles and practice in science and technology, Wiesbaden, Oscar Brandstetter. 